\title{
Desastre natural em Natal-RN: percepções de moradores
}

\author{
Natural disaster in Natal-RN: residents' perceptions \\ Desastre natural en Natal-RN: percepciones de los residentes
}

Recebido: 17/11/2021 | Revisado: 24/11/2021 | Aceito: 26/11/2021 | Publicado: 09/12/2021

Vanessa de Brito Abrantes
ORCID: https://orcid.org/0000-0002-6551-8236
Instituto Federal de Educação, Ciência e Tecnologia do Rio Grande do Norte, Brasil
E-mail: abrantes_vanessa @ hotmail.com
Mario Tavares de Oliveira Cavalcanti Neto
ORCID: https://orcid.org/0000-0002-9248-3382
Instituto Federal de Educação, Ciência e Tecnologia do Rio Grande do Norte, Brasil
E-mail: mario.tavares@ifrn.edu.br

\begin{abstract}
Resumo
Os desastres naturais tem sido uma preocupação mundial, tendo em vista que podem ocasionar perdas materiais, humanas e ambientais. Eles foram responsáveis por $45 \%$ de todas as mortes nos últimos 50 anos, em virtude das mudanças climáticas e dos eventos extremos. A cidade de Natal-RN tem sofrido com alguns eventos de risco que deixam a população vulnerável aos perigos naturais. Desse modo, o presente estudo trata sobre o desastre natural acontecido no bairro de Mãe Luiza em 2014, através de relatos de residentes. O objetivo principal é analisar a percepção dos residentes quanto ao risco a desastres naturais. Para orientar as reflexões este estudo mobiliza, principalmente, temas relacionados a desastres naturais e percepção à luz da fenomenologia. A metodologia tem base qualitativa, natureza exploratória e descritiva, está baseada em entrevistas, realizadas presencialmente, tendo sido tomadas as precauções necessárias à realização de pesquisa com seres humanos, de acordo com os princípios e procedimentos da Comissão Nacional de Ética (CONEP) e do Comitê de Ética em Pesquisa (CEP). Os resultados mostraram, com base nas questões formuladas, dificuldades na compreensão do risco de movimento de massa. Constatou-se que alguns residentes não têm a percepção sobre o risco da ocorrência de desastres. Sendo fundamental, portanto, a concepção de programas de conscientização e capacitação sustentável para garantir seu sucesso com a participação da população local e, assim, implementar a gestão de desastres naturais com base na comunidade estudada.
\end{abstract}

Palavras-chave: Desastre natural; Risco; Percepção; Mãe Luiza.

\begin{abstract}
Natural disasters have been a global concern, considering that they can cause human and environmental material losses. They were responsible for $45 \%$ of all deaths in the last 50 years, due to climate change and extreme events. The city of Natal-RN has suffered from some risk events that leave the population vulnerable to natural hazards. Thus, this study deals with the natural disaster that happened in the neighborhood of Mãe Luiza in 2014, through reports from residents. The main objective is to analyze the residents' perception of the risk of natural disasters. To guide the reflections, this study mainly mobilizes themes related to natural disasters and perception in the light of phenomenology. The methodology is qualitative, exploratory and descriptive in nature, based on in-person interviews, taking the necessary precautions to carry out research with human beings, in accordance with the principles and procedures of the Comissão Nacional de Ética (CONEP) and the Comitê de Ética em Pesquisa (CEP). The results showed, based on the formulated questions, difficulties in understanding the risk of mass movement. It was found that some residents do not have a perception about the risk of disasters occurring. Therefore, it is essential to design sustainable awareness and training programs to ensure their success with the participation of the local population and, thus, implement natural disaster management based on the studied community.
\end{abstract}

Keywords: Natural hazards; Risk; Perception; Mãe Luiza.

\section{Resumen}

Los desastres naturales han sido una preocupación mundial, considerando que pueden causar pérdidas materiales, humanas y ambientales. Fueron responsables del $45 \%$ de todas las muertes en los últimos 50 años, debido al cambio climático y eventos extremos. La ciudad de Natal-RN ha sufrido algunos eventos de riesgo que dejan a la población vulnerable a los peligros naturales. Así, este estudio aborda el desastre natural ocurrido en el barrio de Mãe Luiza en 2014, a través de informes de los vecinos. El objetivo principal es analizar la percepción de los residentes sobre el riesgo de desastres naturales. Para orientar las reflexiones, este estudio moviliza principalmente temas relacionados con los desastres naturales y la percepción a la luz de la fenomenología. La metodología es de naturaleza cualitativa, exploratoria y descriptiva, basada en entrevistas presenciales, tomando las precauciones necesarias para realizar 
investigaciones con seres humanos, de acuerdo con los principios y procedimientos de la Comisión Nacional de Ética (CONEP) y el Comité de Ética en Investigación. (CEP). Los resultados mostraron, a partir de las preguntas formuladas, dificultades para comprender el riesgo del movimiento de masas. Se encontró que algunos residentes no tienen una percepción del riesgo de que ocurran desastres. Por lo tanto, es fundamental diseñar programas sostenibles de sensibilización y capacitación que aseguren su éxito con la participación de la población local y, así, implementar la gestión de desastres naturales con base en la comunidad estudiada.

Palabras clave: Desastre natural; Riesgo; Percepción; Mãe Luiza.

\section{Introdução}

Os desastres naturais tem sido uma preocupação mundial, tendo em vista que podem ocasionar perdas materiais, humanas e ambientais. $\mathrm{O}$ registro de desastres naturais vem aumentando ultimamente, isso se deve, principalmente, ao aumento da população, a ocupação humana e ao intenso processo de urbanização e industrialização. A impermeabilização do solo, o adensamento das construções, a poluição do ar são alguns fatores que contribuem para a ocorrência de desastres (Batista et al., 2021).

Eles foram responsáveis por $45 \%$ de todas as mortes nos últimos 50 anos em virtude das mudanças climáticas e dos eventos extremos. O "Atlas de Mortalidade e Perdas Econômicas de Extremos de Tempo, Clima e Água" produzido pela Organização Meteorológica Mundial (OMM) e pelo Escritório das Nações Unidas para a Redução do Risco de Desastres (UNDRR) mostra que, de 1970 a 2019, os desastres naturais equivaleram a 50\% de todos os desastres, $45 \%$ de todas as mortes reportadas no período e 74\% de todas as perdas econômicas (OMM \& UNDRR, 2021).

No Brasil, os desastres estão relacionados, principalmente, com fenômenos climáticos, aumentados pela ação do homem, os mais comuns são, a seca, a erosão e os deslizamentos (Santos, 2007). Em Natal-RN, tem sido recorrente as ocorrências de deslizamento de solo, tendo ocorrido no bairro de Mãe Luiza em 2014 o mais grave deles, em virtude da quantidade de perdas, desabrigados e do prejuízo ambiental (Cordeiro, 2018).

Por isso a percepção daqueles que convivem com o risco é tão importante. Ela refere-se à visão de mundo, do meio ambiente natural e antrópico. É uma experiência em grupo ou particularizada. É em suma uma avaliação que se faz do ambiente (Oliveira, 2001). Os estudos sobre percepção podem demonstrar relevantes aspectos sobre relações estabelecidas entre as pessoas e os ambientes ameaçados por acidentes. Assim como, podem fornecer subsídios ao planejamento e à gestão urbana e ambiental, pois respondem questões que estão fora da área de alcance dos métodos convencionais empregados pelas ciências naturais (Souza \& Zanella, 2009).

Desse modo, buscando contribuir com a discussão sobre a percepção a desastres naturais, o tema deste estudo está ancorado no bairro de Mãe Luiza, localizado em Natal, Rio Grande do Norte, onde aconteceu, em 2014, movimento de massa deflagrado por intensas chuvas, além de problemas relacionados ao rompimento de tubulações de águas pluviais (Brasil, 2014).

Levando em consideração a importância da percepção para que se evite a ocorrência de novos desastres naquela área, tem-se como pergunta de partida: como os residentes do bairro de Mãe Luiza percebem os riscos e se comportam diante deles? E, quais são as medidas adotadas por eles que favorecem a convivência com o perigo? E consequente objetivo: analisar a percepção dos residentes do bairro de Mãe Luiza, Natal-RN quanto a desastres naturais, do tipo movimento de massa.

A partir do desastre ocorrido em 2014, no bairro de Mãe Luiza, foram realizados trabalhos que direta ou indiretamente colocaram algum aspecto dele em questão. Para identificação desses trabalhos foi realizada pesquisa no repositório da Universidade Federal do Rio Grande do Norte (UFRN) e do Instituto Federal de Educação, Ciência e Tecnologia do Rio Grande do Norte (IFRN). No entanto, há lacunas na literatura quanto a utilização da percepção como meio de busca de informações e dados das populações para desenvolvimento de ações que visem a prevenção de desastres naturais.

Após ter ocorrido o desastre, Maciel et al. (2015) realizaram estudo sobre vulnerabilidade ambiental em que foram estabelecidas cinco classes de índice de vulnerabilidade socioambiental para o bairro de Mãe Luiza, dentre eles o muito baixo, 
baixo, médio, alto e muito alto. Por fim, foram encontrados sete núcleos de muito alta vulnerabilidade. Silva (2016) tratou da solidariedade e resiliência comunitária em situação de desastre e concluiu que ações de solidariedade, direcionadas a gestão de riscos devem ser incentivadas nas comunidades, visando desenvolver e melhorar a resiliência comunitária e global do sistema. Cordeiro (2018) apontou índice de risco para áreas de risco, em que o bairro de Mãe Luiza está incluído, e mensurou as áreas susceptíveis a erosão de solo. Chegou à conclusão que o mapa de risco a erosão pode ser utilizado no zoneamento de risco dos desastres naturais por erosão de solo. Lima e Almeida (2018) vincularam desastre ambiental e ordenamento territorial. Os resultados apontaram para o acontecimento de problemas relacionados ao planejamento e ordenamento territorial na produção do desastre ocorrido no bairro.

Contudo, não há trabalhos que tratem da opinião dos moradores da área sobre o desastre natural. Assim como, até então, não foi considerado que a percepção dos riscos a desastres é essencial para a prevenção e mitigação dos danos causados pelo evento e que esses fatores estão fortemente ligados, as ações dos moradores, e a ocupação do território.

Trata-se, portanto, de pesquisa de base qualitativa, natureza exploratória, descritiva de caráter fenomenológico em que a percepção e compreensão dos indivíduos sobre determinado objeto são relevantes. Tem-se, por conseguinte, relatos de residentes do bairro de Mãe Luiza, no tocante ao risco a desastres naturais (Gil, 2008).

\section{Revisão de Literatura}

Desastres naturais são eventos causados pela natureza que acarretam danos aos seres humanos e causam perturbação ao sistema social. Podem ser desencadeados pelo homem ou pela natureza (Tominaga \& Santoro, 2009).

Vinculado ao desastre, existe o risco que pode ser entendido como objeto social, percepção do perigo, possui relação intrínseca com o indivíduo e grupos sociais. Relaciona-se com o contexto histórico e modos de ocupação do território, para Veyret (2007, p. 30),

[...] o risco é uma construção social. A percepção que os atores têm de algo que representa perigo para eles próprios, para os outros e seus bens, contribui para construir o risco que não depende unicamente de fatos ou processos objetivos.

O risco é, também, o resultado da interação entre ameaça e vulnerabilidade. A noção de risco se estabelece com base na relação entre o homem e o seu ambiente, em um processo de mútua influência. Segundo Souza e Zanella (2009, p. 12),

A ameaça está relacionada às condições físico-naturais do terreno ou da área ocupada, indicando sua maior ou menor suscetibilidade à ocorrência de fenômenos que podem colocar o homem em situação de perigo, como os escorregamentos, as inundações, os terremotos, os furacões etc. Já a vulnerabilidade diz respeito às condições objetivas e subjetivas de existência, historicamente determinadas, que originam ou aumentam a predisposição de uma comunidade a ser afetada pelos possíveis danos decorrentes de uma ameaça.

De acordo com a Classificação e Codificação Brasileira de Desastres (COBRADE) os desastres são divididos em cinco grupos: geológico, hidrológico, meteorológico, climatológico e biológico. Focaremos nesta pesquisa nos desastres do grupo geológico, subgrupo movimento de massa, tipo deslizamentos, subtipo deslizamento de solo e ou rocha (COBRADE 1.1.3.2.1), como observa-se na Figura 1 (Brasil, 2019). 
Figura 1: COBRADE.

\section{CLASSIFICACÃO E CODIFICACÃ̃O BRASILEIRA DE DESASTRES (COBRADE)}

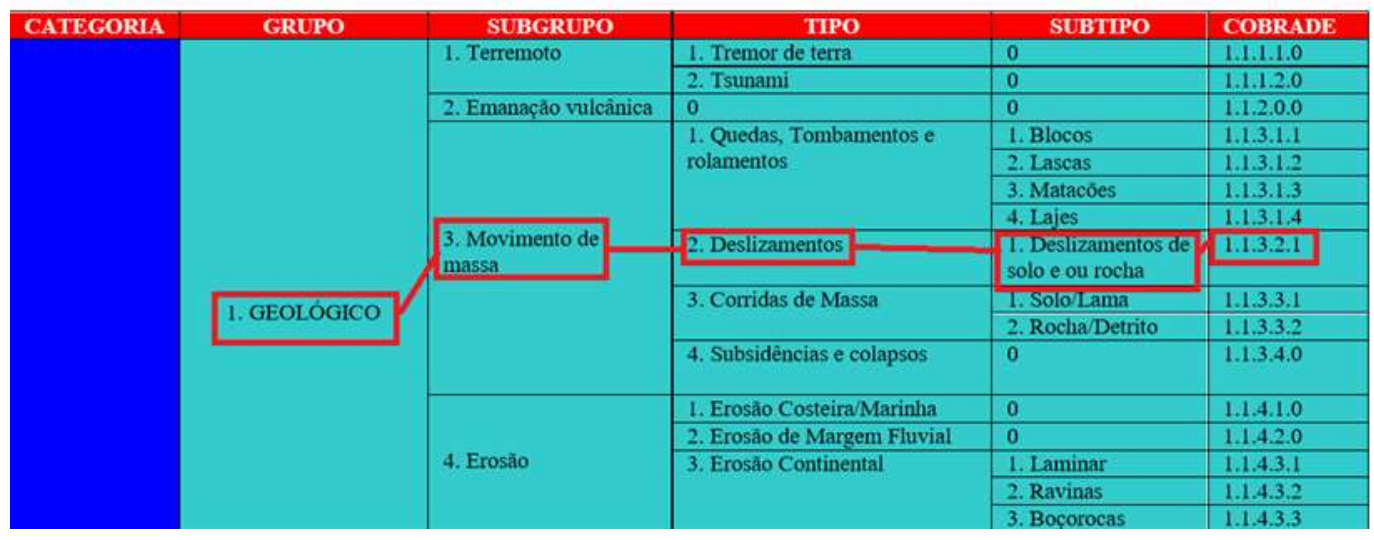

Fonte: adaptado de Brasil (2019).

Os movimentos de massa estão associados a deslocamentos rápidos de solo e rocha de uma encosta onde o centro de gravidade desses materiais se desloca para fora e para baixo desta feição. Associam-se aos condicionantes geológicos e geomorfológicos, aos aspectos climáticos e hidrológicos, à vegetação e à ação do homem com relação ao uso e ocupação do solo (CEPED, 2012).

Tratando agora da percepção da população afetada por desastres, ela está relacionada ao espaço ocupado, e este reflete os círculos sociais e culturais em que a pessoa está exposta, como também as restrições e potencialidades espaciais que mediam sua compreensão dos perigos ambientais (Marandola \& Modesto, 2012).

A percepção é um aspecto importante em relação ao comportamento diante dos riscos, principalmente no que se refere às medidas preventivas. Logo que a percepção de pessoas residentes em áreas propensas a riscos é conhecida, estratégias efetivas de informação sobre medidas de proteção podem ser planejadas (Plapp \& Werner, 2006).

Em relação a Fenomenologia, é a filosofia que trata sobre o estudo das essências na existência. Ela teve origem a partir das preocupações de Edmund Husserl (1859-1938), com as conceituações tradicionais e a ciência cartesiana, ele, então, buscou contestar sua existência. Por isso, na fenomenologia não há explicação ou análise de fatos, mas sim a descrição de como eles ocorrem para cada indivíduo (Merleau-Ponty, 1999).

A Fenomenologia pode ser entendida como outro olhar sobre a ciência positivista. Apesar de possuir o mundo como mesmo objeto de estudo, há métodos diferentes de análise do objeto, em que a percepção, sensação e compreensão do indivíduo são de fundamental importância.

Recorrendo a Merleau-Ponty (1999, p. 3), “[...] a ciência não tem e não terá jamais o mesmo sentido de ser que o mundo percebido, pela simples razão de que ela é uma determinação ou uma explicação dele”. Pode-se dizer, então, que a própria ciência advém do mundo percebido, e age em favor dele. E é nesse mundo percebido que está inclusa a percepção dos indivíduos, no caso deste artigo, indivíduos que residem área de risco a desastres naturais.

Passamos, pois, a falar sobre o meio, quando é área de risco a desastres naturais há alguns aspectos que podem auxiliar no controle dos desastres. A gestão de riscos apresenta diretrizes a serem realizadas antes, durante e após os desastres. Segue abaixo Tabela 1 que demostra algumas medidas a serem adotadas. 
Tabela 1: Principais aspectos da gestão de riscos no Brasil.

\begin{tabular}{|c|c|}
\hline & Gestão de risco a desastres no Brasil \\
\hline \multirow{2}{*}{$\begin{array}{l}\text { Informação e } \\
\text { conhecimento }\end{array}$} & Mapeamento e reconhecimento das áreas de risco. \\
\hline & $\begin{array}{l}\text { Transparência nas informações coletadas pré e pós-eventos que constituem base para o } \\
\text { trabalho de redução de riscos e impactos. }\end{array}$ \\
\hline $\begin{array}{l}\text { Direcionamento de } \\
\text { políticas públicas }\end{array}$ & $\begin{array}{l}\text { Criação de sistema integrado para receber informações sobre monitoramento de áreas de } \\
\text { risco, aliado à compilação de dados que demonstrem a recorrência e intensidade de } \\
\text { desastres, indicando para onde as políticas públicas preventivas devem ser direcionadas. }\end{array}$ \\
\hline \multirow[t]{3}{*}{ Prevenção } & Operacionalização de um sistema gestor que priorize os riscos e não os desastres. \\
\hline & Acompanhamento e monitoramento das áreas de risco \\
\hline & Capacitação profissional de agentes relacionados à prevenção de desastres. \\
\hline \multirow{2}{*}{$\begin{array}{l}\text { Resposta aos } \\
\text { desastres e } \\
\text { recuperação }\end{array}$} & Agilidade e eficiência do sistema gestor perante situações de crise. \\
\hline & Justiça na distribuição do orçamento destinado a esta finalidade. \\
\hline
\end{tabular}

Fonte: adaptado de Pascoalino e Almeida (2014).

A realização da gestão de risco no bairro de Mãe Luiza é imprescindível, já que o desastre ocorrido em 2014 afetou diversas habitações e deixou vários desabrigados. Algumas casas foram totalmente destruídas, e outras foram interditadas pela Defesa Civil. Conforme Tabela 2 que demonstra o quantitativo de habitações afetadas.

Tabela 2: Quantitativo de habitações afetadas pelo desastre ocorrido em 2014, no bairro de Mãe Luiza, Natal-RN.

Habitações afetadas por desastre em 2014

\begin{tabular}{cc}
\hline Totalmente destruídas & 26 \\
\hline Parcialmente destruídas & 46 \\
\hline Interditadas por prevenção & 88 \\
\hline Total & 160 \\
\hline
\end{tabular}

Fonte: Autores (2020), com base em dados fornecidos pela SEHARPE.

Nesse sentido, ações de prevenção a novos desastres são necessárias. Tendo em vista que o bairro é classificado como área de risco - por ser um setor susceptível a deslizamentos ou outros problemas relacionados a ocupação de complexos dunares - pelo Plano Municipal de Redução de Riscos (PMRR) desde 2008, antes mesmo que o desastre acontecesse em 2014 (Natal, 2008). E também, segundo Cordeiro (2018) o bairro de Mãe Luiza possui índice de risco a erosão muito alto, em uma escala que compreende os níveis: muito baixo, baixo, médio, alto e muito alto. Desse modo, deve haver, no mínimo, acompanhamento e monitoramento da área.

\section{Materiais e Métodos}

A pesquisa tem base qualitativa, natureza exploratória, pois permite a obtenção de novas percepções e ideias, é, também, descritiva já que os resultados foram obtidos em sua totalidade pelos relatos dos residentes do bairro de Mãe Luiza. Além disso, o estudo tem caráter fenomenológico em que a percepção e compreensão dos indivíduos sobre determinado objeto são relevantes.

O método fenomenológico, leva em consideração as experiências de cada indivíduo, subjetivamente, para MerleauPonty (1999, p. 286): “O objeto só se determina como um ser identificável através de uma série aberta de experiências possíveis, e só existe para um sujeito que opera essa identificação.” Ressalta-se que o método fenomenológico dificilmente é encontrado em trabalhos sobre desastres que possuem mais características técnicas e naturalistas (Souza \& Zanella, 2009).

Portanto, baseando-se também em Lakatos e Marconi (2011) foram elaboradas entrevistas com roteiro semiestruturado, possibilitando maior flexibilidade e facilidade de formular as perguntas no momento da conversação. 
A amostra foi selecionada aleatoriamente, o critério utilizado para definir a quantidade de entrevistados foi o de “saturação". Ele é usado para encontrar um número de entrevistados - não definido inicialmente - no desenrolar da investigação. Quando o assunto da entrevista começa a se repetir e aumentar o número de sujeitos entrevistados, pouco acrescenta de significativo à pesquisa, podendo, então, realizar mais algumas entrevistas e depois parar (Sá, 1998).

A população de interesse para realização das entrevistas foi composta pelos afetados diretamente pelo desastre, assim como pelos afetados indiretamente - residentes do bairro que moram próximo à área do desastre.

As entrevistas foram realizadas, presencialmente, com 16 residentes do bairro de Mãe Luiza entre os dias 17 e 18 de dezembro de 2019, tendo sido tomadas as precauções necessárias à realização de pesquisa com seres humanos, de acordo com os princípios e procedimentos da Comissão Nacional de Ética (CONEP) e do Comitê de Ética em Pesquisa (CEP), preservando o anonimato de cada participante (Brasil, 2013, 2016).

Basearam-se em quatro perguntas principais: 1) tempo de residência no bairro; 2) Se foi vítima do desastre natural; 3) Se possui segurança em relação a possibilidade de acontecimentos de novos desastres no bairro; 4) Ações que realiza, ou considera importante serem realizadas para minimizar situações de risco natural.

Após a realização das entrevistas, os dados foram analisados baseando-se na literatura de Bardin (2011). Ele trata da análise de conteúdo, método de tratamento e análise de informações através de coleta de dados, consubstanciadas em um documento. A técnica se aplica a análise de textos escritos, ou de qualquer comunicação (oral, visual, gestual) reduzida a um texto ou documento (Chizzotti, p. 98, 2010).

\subsection{Caracterização da Área}

A área está localizada na Zona Administrativa Leste do Município de Natal, no Rio Grande do Norte (Figura 3), observa-se no mapa na cor cinza o estado do Rio Grande do Norte, em azul o município de Natal, destacando-se em amarelo o bairro de Mãe Luiza. O bairro foi criado pela Lei $\mathrm{n}^{\circ} 794$ em 1958. É uma zona de interesse social, margeado pela Zona de Proteção Ambiental (ZPA 10). A Lei no 4.663, de 1995 o define como Área Especial de lnteresse Social (AEIS), onde existe uma série de limitações quanto ao uso e ocupação do solo, principalmente nas áreas de encostas e próximas ao Farol (NATAL, 2010). 
Figura 3: Localização do bairro de Mãe Luiza, Natal-RN.

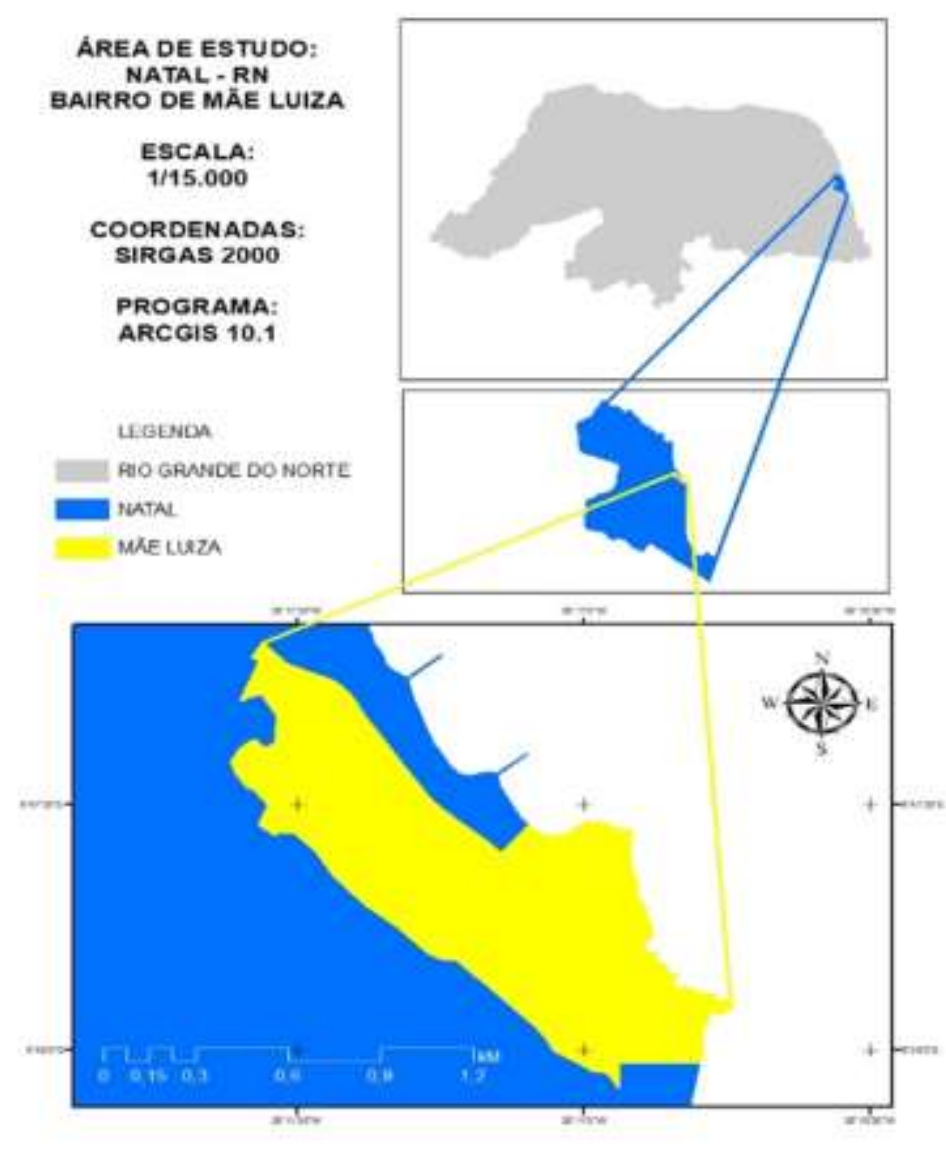

Fonte: Autores (2020).

A Figura 4 indica a variação de altitude em relação ao nível do mar, através das curvas de nível (linhas na cor verde), pode-se constatar diversas diferenças de altitude que vão de 78 metros na parte mais alta (localizado próximo ao limite territorial do bairro, demarcado na cor cinza), até 4 metros, na parte mais baixa, característica do relevo de dunas. 
Figura 4: Mapa Hipsométrico do bairro de Mãe Luiza.

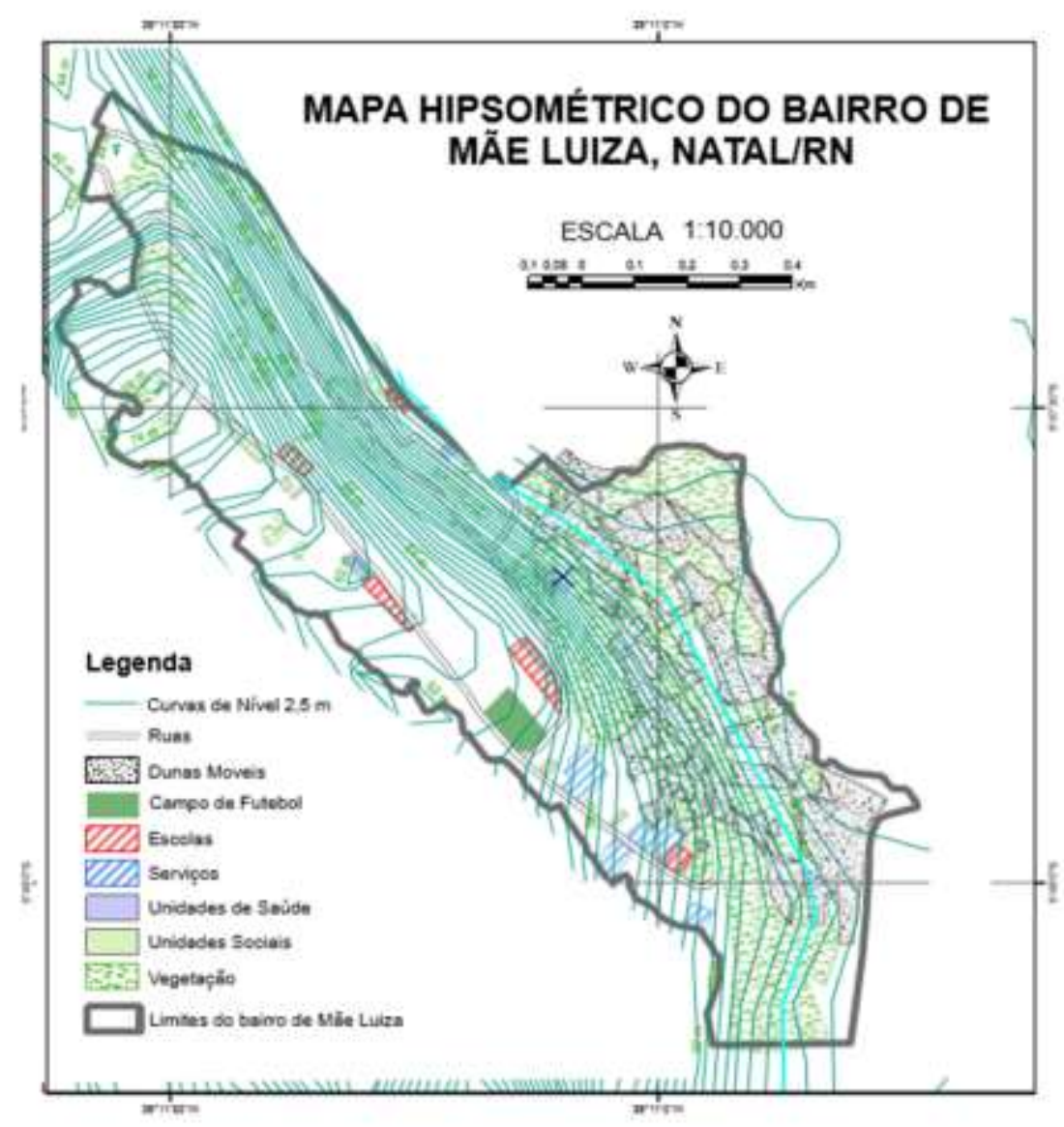

Fonte: Autores (2021).

Já a Figura 5 demonstra alguns pontos de instabilidade com alto risco a erosão no bairro de Mãe Luiza, destacados na cor vermelha, em uma escala que compreende os níveis: muito baixo, baixo, médio, alto e muito alto. 
Research, Society and Development, v. 10, n. 16, e131101623465, 2021

(CC BY 4.0) | ISSN 2525-3409 | DOI: http://dx.doi.org/10.33448/rsd-v10i16.23465

Figura 5: Risco a erosão no bairro de Mãe Luiza.

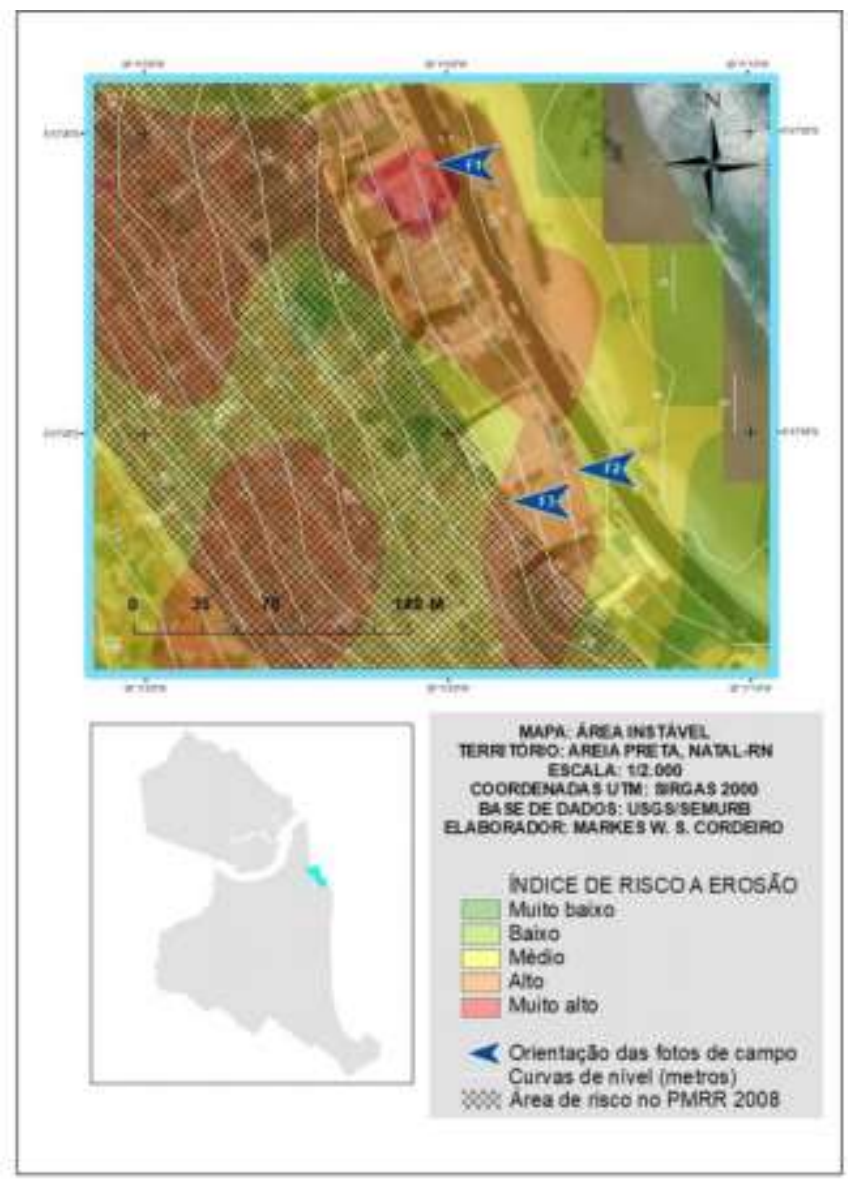

Fonte: Cordeiro (2018).

\subsection{Caracterização da População}

As entrevistas foram realizadas com 16 residentes do bairro de Mãe Luiza, sendo 10 do gênero feminino (62\%) e 6 do gênero masculino (38\%). Demonstrada na Figura 6.

Figura 6: Percentual do gênero dos entrevistados.

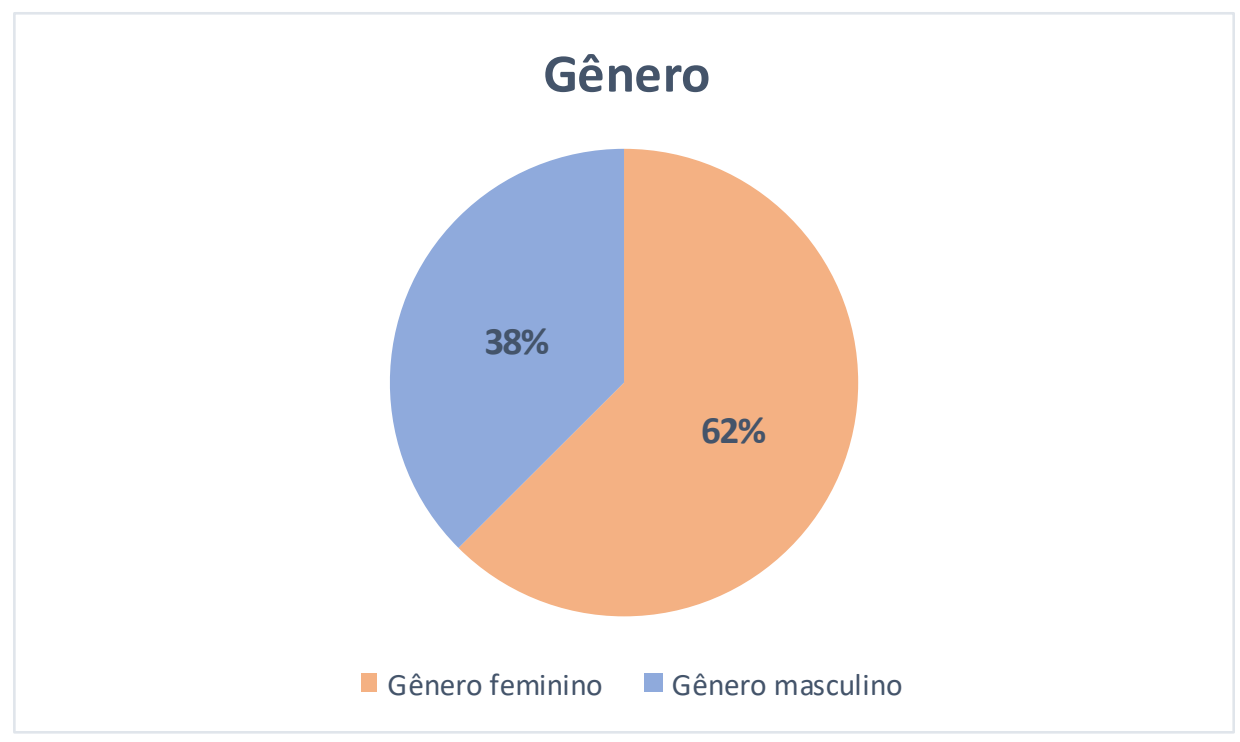

Fonte: Autores (2021). 
A faixa etária (Figura 7) dominante entre eles foi a de (45-49) anos com 4 representantes (25\%), seguida da faixa etária de (40-44) anos com 3 representantes (18,75\%). A faixa etária mais alta encontrada foi a de (75-79) anos com 2 representantes (12,5\%) e a mais baixa de (30-34 anos) com 2 representantes (12,5\%). As outras faixas etárias (35-39) apenas 1 representante $(6,25 \%),(50-54)$ com 2 representantes $(12,5 \%)$ e $(60-64)$ com 2 representantes $(12,5 \%)$.

Figura 7: Percentual da faixa etária.

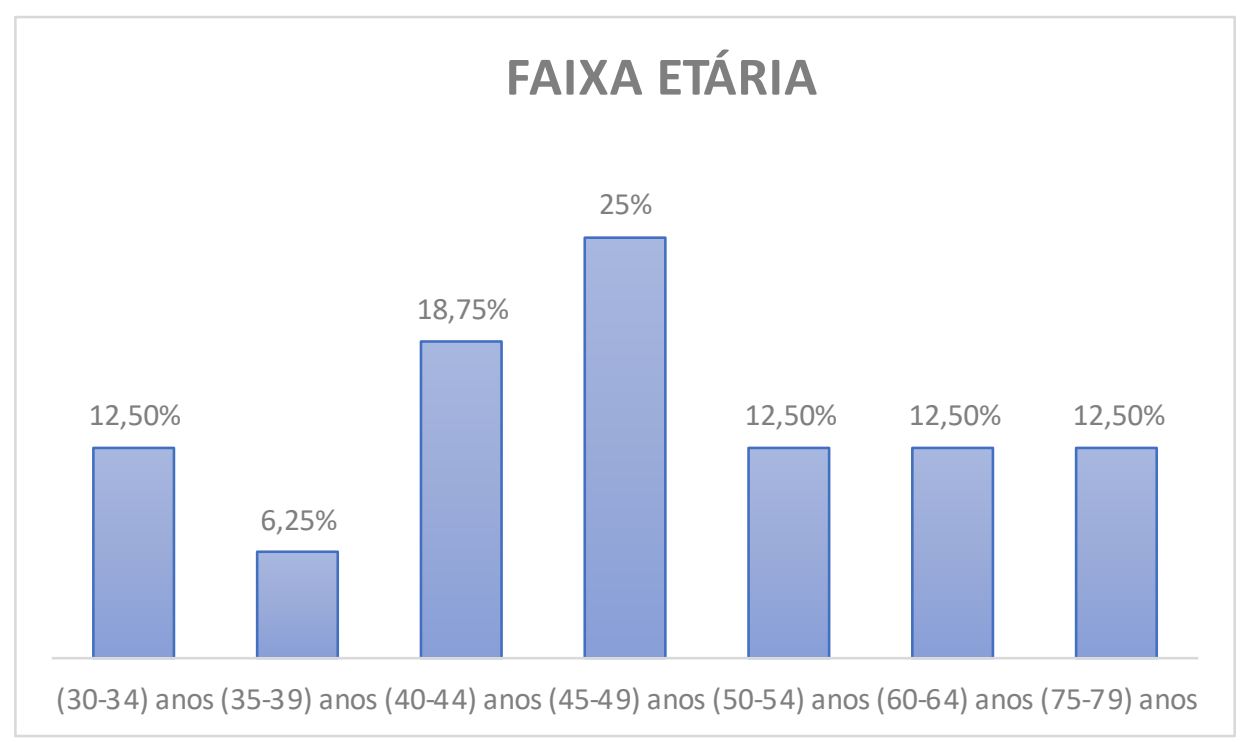

Fonte: Autores (2021).

A profissão dos entrevistados foi variada, havia donas de casas, professores, comerciantes informais, agente comunitário de saúde, aposentados, técnico de enfermagem. A profissão mais representativa foi a de comerciante informal com 4 representantes $(25 \%)$.

O nível de instrução (Figura 8) com maior número de representantes foi o fundamental com 7 pessoas (43,75\%), seguido do médio com 5 pessoas $(31,25 \%)$, superior com 3 pessoas $(18,75 \%)$ e sem instrução com 1 pessoa $(6,25 \%)$. Por fim, o tempo médio de residência foi de 30 anos.

Figura 8: Percentual de escolaridade.

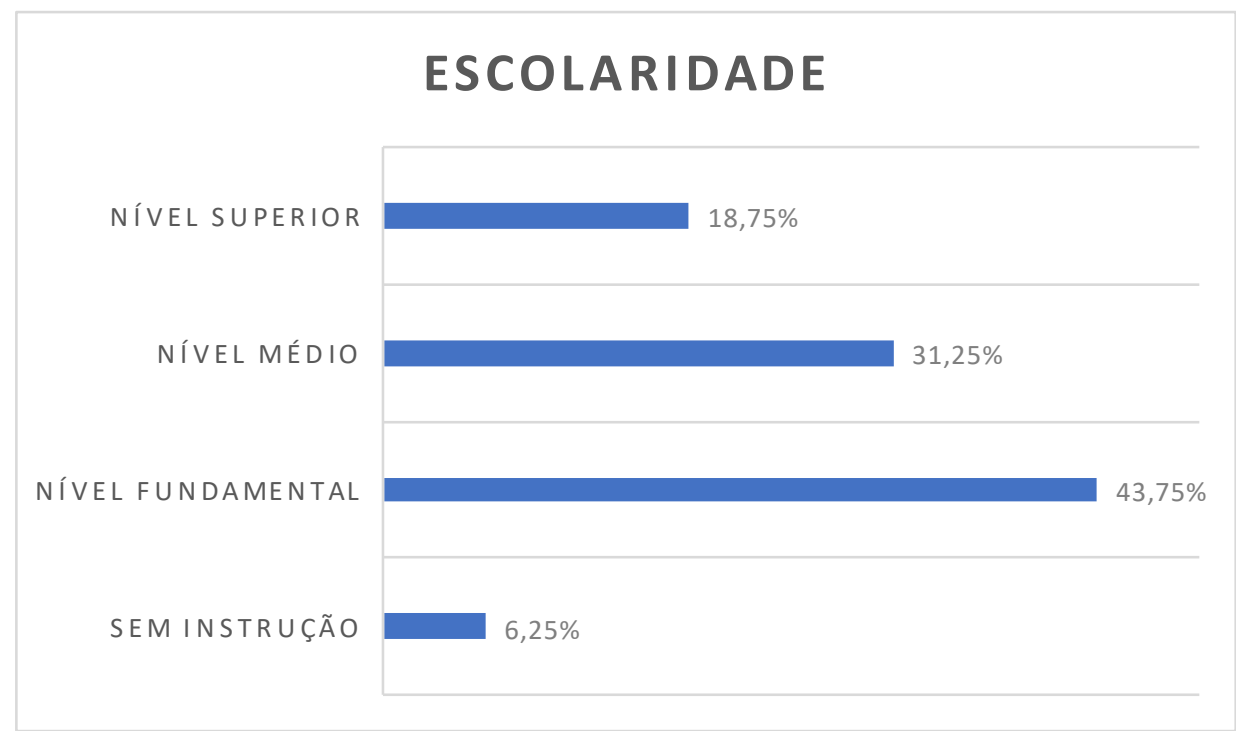

Fonte: Autores (2021). 


\section{Resultados e Discussão}

Para entender a relação de pertencimento ao território, foram perguntados sobre tempo de residência no bairro, seguem abaixo algumas respostas:

“Moro Rua Guanabara. Eu estou com 76 anos vim para cá quando tinha 12 anos, há 64 anos, e não quero sair daqui porque aqui é o lugar bom de se morar. Pois é, eu vim para cá tinha 12 anos, casei meus filhos todos aqui, estudou todos nesse colégio aí e nenhum deu para marginal. Tenho 7 filhos."

"Vai fazer 37 anos. Nunca me mudei, a gente só saiu daqui quando aconteceu o desastre que a gente foi morar ali no Novo Mundo, ali perto do Farol. Fui morar em casa alugada, que recebia o auxílio, a gente recebia todo mês."

“Moro há 28 anos."

O tempo médio de residência encontrado nas respostas foi de 30 anos. Com base nos trechos "64 anos", "Vai fazer 37 anos" e "Moro há 28 anos" pode-se observar que apesar do bairro ser área de risco, é habitado há bastante tempo, afinal foi criado por lei desde 1958, possui saneamento, drenagem, coleta de lixo, ruas asfaltadas, transporte público, escolas, posto de saúde, praças, enfim, possui estrutura necessária para a convivência social.

Dois entrevistados que foram afetados pelo desastre relataram situações importantes durante o acidente acontecido em 2014:

"Tive a casa afetada, porque rachou um pouquinho lá na frente e passou um ano interditada, por causa do buraco. Retirei todas as coisas de dentro da minha casa, enquanto estava interditada, porque estava havendo muitos saques. Tanto tem culpa a prefeitura, como a CAERN."

"Eu fui para a audiência que teve agora essa semana, dia 10, e assim só gente da prefeitura e CAERN, cada um que defende o outro. Aí bota a culpa na população, que sujava, que molhava."

Os seguintes trechos: "Tanto tem culpa a prefeitura, como a CAERN", "Eu fui para a audiência que teve agora essa semana, dia 10, [...] só gente da prefeitura e CAERN, cada cá que defende o outro" demonstram que a Prefeitura Municipal de Natal e a Companhia de Águas e Esgotos do Rio Grande do Norte (CAERN) foram responsabilizadas pelo desastre ocorrido em Mãe Luiza, em ação civil pública ingressada pelo Ministério Público do Rio Grande do Norte (MPRN). A ação civil pública baseou-se em relatório técnico elaborado por equipe da FUNPEC/UFRN.

Continuando com os relatos,

"Moro na João XXIII. Só meus parentes moram nessas casas aqui. Quando teve o desabamento eles foram para casa de parentes. Depois a prefeitura agilizou o auxilio aluguel. Ai foram se organizando."

"Estava tudo caindo aí, aqui dentro de casa a gente fechou as portas. No outro vieram tirar a mudança, todo mundo tinha que tirar a mudança. Todo mundo tinha que alugar seus cantos. Aqui passou um bocado de tempo fechado, demorei uns 5 dias para arrumar uma casa, arrumei lá na João XXIII. Pagamos aluguel e fomos para dentro da casa. Aí a prefeitura ajudou a pagar o aluguel, recebi um ano de aluguel e foi desinterditada. Só que quando vieram desinterditar eles colocaram assim: "em observação". Não desinterditaram totalmente, né? Eu acho que quando tá na observação é porque tem que alguma coisa fazer."

O auxílio aluguel citado nos trechos: "Depois a prefeitura agilizou o auxílio aluguel” e "Aí a prefeitura ajudou a pagar o aluguel, recebi um ano de aluguel", trata-se do Programa Social de Auxílio Moradia instituído pelo Decreto no 10.352 de 15 de julho de 2014 (Natal, 2014). 
De acordo com informações prestadas pela Secretaria de Habitação, Regularização Fundiária e Projetos Estruturantes (SEHARPE), o valor do Auxílio Moradia consiste em um salário mínimo concedido para o aluguel de habitação, que pode ser realizado em todo o município de Natal.

Para compreender às relações de convivência e adaptação com o risco ambiental, os entrevistados foram perguntados sobre se sentirem seguros em relação ao acontecimento de novos desastres, seguem posteriormente alguns relatos:

"Eu me sinto. Depois que fizeram um serviço bem feito viu. Agora foi bem feito viu. Essa rua aqui eles cavaram todinha tiraram os canos velhos que tinha e colocaram tudo novo, uns canos bem grossos, entendeu? Tanto daqui, como daí de cima também, não tem perigo, se eles quisessem fazer a casa do povo aí, fazia, porque não tem perigo."

"Eu me sinto. Eu me sinto mais segura. Tem gente que não se sente segura não, mas eu sinto. Vem chuva, chove chuva aí, tudo e até agora não abala em nada aqui. Apesar que tem alguns canto aí que tá querendo afundar né? Lá para frente, ali para acolá, mas aqui, não. Agora tem aí na escadaria, eu não vejo não, as pessoas é que falam que tá rachado um pouco, aí eu não sei. Mas que tá muito seguro aqui tá. Por que foi muito bem feito, porque as tubulação que eles fizeram foi melhor, porque antigamente as tubulação era pequena, mas agora são grande é melhor para sair água. Antigamente essas bichinha aqui era muito pequena, esses buraco de correr água."

"Não. Inclusive eu estou do mesmo jeito que deixaram, do jeito que ficou no acidente, ainda ficou do mesmo jeito. A minha casa tem uma rachadura lá no canto, o bueiro está do mesmo jeito, destampado. Tem um bueiro que é no meio do meu quintal e eu nunca pude fazer nada. Porque justamente quando enche... ontem mesmo estourou um bueiro bem ali."

"Não. Sinto medo quando chove. Tenho medo porque aqui é área de risco, por ter sido construído em cima de dunas."

"Eu tenho medo porque eu moro debaixo de um muro de arrimo de mais de 10 metros de altura. Minha casa é feita em baixo desse muro. E depois desse muro tem o meu lá em cima que é mais três metros em cima. Eu só imagino aquilo descendo, acho que eu nunca mais me acho. O muro está em tempo de cair, todo rachado. Só Jesus. Às vezes eu me levanto com medo de ocorrer alguma coisa. Esse ano eu tenho maior medo do inverno."

Diante dos relatos observa-se que alguns residentes se sentem seguros e outros não. Alguns compreendem que mesmo após a realização das obras, o bairro continua sendo considerado área de alto risco e outros não, por entenderem que as obras foram bem realizadas e por isso a área não oferece mais risco. No entanto, a maioria dos entrevistados não se sentem seguros, dos 16 entrevistados apenas 6 (37,5\%) se sentiam seguros, sendo eles 4 do gênero feminino, e 2 do gênero masculino, tinham faixa etária mais elevada, alguns aposentados, e com nível fundamental.

Os entrevistados foram perguntados sobre as ações realizadas no bairro com vistas à prevenção de novos desastres:

"Aqui mesmo na Guanabara passa carro de lixo, duas, três vezes no dia. Passa de manhã, passa ao meio dia, passa de tarde, às vezes até no domingo passa. Mas todo dia tem lixo que o povo joga."

"Os moradores protestam quando o saneamento estoura. Em cima do colégio assim, o pessoal joga lixo, joga tudo que não presta. Alguém, assim, para ver se a CAERN aparece, toca fogo, somente."

A situação dos resíduos sólidos citada por dois residentes "[...] todo dia tem lixo que o povo joga." e "Em cima do colégio assim, o pessoal joga lixo, joga tudo que não presta" são ações realizadas por alguns moradores que podem vir a ocasionar novos desastres, tendo em vista que a disposição inadequada dos resíduos sólidos é um dos principais causadores de desastres urbanos (Silva \& Andrade, 2019). Desse modo, o desenvolvimento de programas de educação ambiental é importante para conscientizar a comunidade sobre os riscos do acondicionamento incorreto dos resíduos sólidos (Barreto \& Vilaça, 2018).

Por fim, segue relato de um residente sobre forma de adaptação com o risco:

"Quando está começando a cair os buracos o pessoal vai e bota um cimento para tampar, por que se o muro cair vai derrubando tudo de casa abaixo." 
Dos 16 entrevistados esse foi o único que respondeu, de fato, uma ação realizada pelos moradores. Alguns respondiam que não sabiam, ou mudavam de assunto quando se chegou a essa pergunta. A maioria falava sobre como o desastre aconteceu, para onde foram realocados, mas não citavam ações realizadas por eles que minimizassem o risco. Portanto, pôde-se observar que a consciência, o conhecimento e a percepção do risco foi maior entre as pessoas instruídas e em interação social.

\section{Considerações Finais}

A análise da percepção dos moradores do bairro de Mãe Luiza permitiu concluir que os vínculos existentes entre eles e o local em que vivem são fortes, tendo sido 30 anos o tempo médio de residência no bairro. Apesar disso, a maioria dos residentes sentem-se inseguros quanto ao acontecimento de novos desastres na área.

O descarte de resíduos sólidos de forma inadequada foi identificado como possível causador de novos desastres, demonstrando a necessidade da realização de ações de educação ambiental com vistas ao acondicionamento adequado dos resíduos.

Poucas atitudes foram citadas pelos moradores quanto a realização de ações que previnam desastres. Logo, é fundamental a concepção de programas de conscientização e capacitação sustentável para garantir seu sucesso com a participação da população local e, assim, haver a implementação da gestão de desastres naturais com base na comunidade estudada.

Observou-se que a consciência, o conhecimento e a percepção do risco foi maior entre as pessoas instruídas e em interação social. Diante disso, espera-se que as percepções obtidas sejam capazes de contribuir com futuros trabalhos sobre prevenção a desastres naturais, tendo em vista que poderão revelar outros aspectos sobre a convivência entre o homem e os riscos. Sugere-se, também, a realização de trabalhos que possam analisar a percepção de moradores de outras áreas do município de Natal, já que este estudo está restrito ao bairro de Mãe Luiza.

\section{Referências}

Bardin, L. (2011). Análise de Conteúdo. Edições 70.

Barreto, L. M. \& Vilaça, M. T. M. (2018). Controvérsias e consensos em educação ambiental e educação para o desenvolvimento sustentável. Pesquisa, Sociedade e Desenvolvimento, 7(5), e975167.

Batista, B. A., Correia Filho, W. L. F., Oliveira-Júnior, J. F. De, Santiago, D. de B., \& Santos, C. T. dos. (2021). Evaluation of the urban expansion in the City of Maceió, Alagoas - Northeast of Brazil. Research, Society and Development, 10(11), e253101119537.

Brasil. Conselho Nacional de Saúde. Resolução $n^{\circ}$ 466, de 12 de dezembro de 2012. Aprova normas regulamentadoras de pesquisas envolvendo seres humanos. Brasília: Diário Oficial da União.

Brasil. Conselho Nacional de Saúde. Resolução $n^{\circ}$ 510, de 07 de abril de 2016. Dispõe sobre as normas aplicáveis a pesquisas em Ciências Humanas. Brasília: Diário Oficial da União.

Brasil. (2019). Ministério do Desenvolvimento Regional. Codificação Brasileira de Desastres (COBRADE). http://www.integracao.gov.br/protecao-e-defesacivil/centro-nacional-de-gerenciamento-de-riscos-e-desastres-cenad/entenda-os-desastres.

Brasil. (2014). Serviço Geológico do Brasil. Ação Emergencial para Análise de Risco Remanescente na Comunidade Mãe Luiza NATAL-RN. https://rigeo.cprm.gov.br/jspui/bitstream/doc/22032/3/bairro_mae_luiza_natal_rn_jun2014.pdf

CEPED - Centro Universitário de Estudos e Pesquisas Sobre Desastres. (2012). Atlas brasileiro de desastres naturais 1991 a 2010. v. 1, Brasil. Relatórios Técnicos.

Chizzotti, A. (2010). Pesquisa em ciências humanas e sociais. (11a ed.), Cortez.

Cordeiro, M. W. S. (2018) Índice de risco a erosão e mapeamento das áreas de risco por erosão de solo em Natal-RN [Dissertação de mestrado, Instituto Federal de Educação, Ciência e Tecnologia do Rio Grande do Norte]. https://memoria.ifrn.edu.br/handle/1044/1498?show=full

Gil, A.C. (2008). Métodos e técnicas de pesquisa social. Editora Atlas S.A.

Lakatos, E. M. \& Marconi, M. A. (2011). Metodologia Científica. (6a ed.), Editora Atlas S.A. 
Lima, P. H. \& Almeida, L. (2018). Desastre socioambiental e ordenamento territorial no bairro Mãe Luiza, Natal - RN, Brasil. Revista de Geociências do Nordeste, 4(2), 81-98.

Maciel, A. B. C., Macedo, Y. M. \& Almeida, L. Q. de. (2015). Índice de vulnerabilidade socioambiental (IVSA): estudo de caso do bairro de Mãe Luíza Natal/RN, Brasil em escala de detalhe. Revista de Geologia, 28(2), 101-116.

Marandola Jr, E. \& Modesto, F. (2012). Percepção dos perigos ambientais urbanos e os efeitos de lugar na relação população-ambiente. Revista Brasileira de Estudos de População, 29(1), 7-35.

Merleau-Ponty, M. (1999). Fenomenologia da percepção. Trad. Carlos Alberto Ribeiro de Moura. (6a ed.), Martins Fontes.

Natal. Decreto $\mathrm{n}^{\circ} 10.352$ de 15 de julho de 2014. Regulamenta a Lei 6.473, de 10 de julho de 2014, que instituiu o Programa Social de Auxílio Moradia, integrante das políticas públicas de Assistência Social e Habitação. Diário Oficial do Município, Natal, 16 de julho de 2014. http://portal.natal.rn.gov.br/_anexos/publicacao/dom/dom_20140716.pdf

Natal. (2010). Secretaria de Meio Ambiente e Urbanismo. Bairros de Natal. https://www.natal.rn.gov.br/semurb/paginas/ctd-102.html

Natal. (2008). Secretaria Municipal de Meio Ambiente e Urbanismo. Plano municipal de redução de riscos do município do Natal. https://natal.rn.gov.br/semurb/paginas/ctd-102.html

Nunes, L.H. (2009). Compreensões e ações frente aos padrões espaciais e temporais de riscos e desastres. Territorium, 16, 179-189.

Oliveira, L. (2001). Percepção ambiental. Revista Geografia e Pesquisa, 6, 56-72.

OMM \& UNDRR. (2021). Organização Meteorológica Mundial, Escritório das Nações Unidas para a Redução do Risco de Desastres. Atlas de Mortalidade e Perdas Econômicas de Extremos de Tempo, Clima e Água. EUA: OMM, UNDRR. https://brasil.un.org/pt-br/142679-desastres-naturais-foram-responsaveispor-45-de-todas-mortes-nos-ultimos-50-anos-mostra-omm

Pascoalino, A. \& Almeida, L. Q. De. (2014). Desastres naturais e gestão de risco no Brasil: características e contributos para o ordenamento territorial. Coimbra.

Plapp, T \& U. Werner, U. (2006). Understanding risk perception from natural hazards: examples from Germany. RISK 21 - Coping with risks due to natural hazards in the 21 st century, Germany: Taylor and Francis, 101-108.

Rio Grande do Norte. (2016). Ministério Público Estadual. Desastre de Mãe Luiza: conclusões do Ministério Público e encaminhamentos. http://www.mprn.mp.br/portal/inicio/meio-ambiente/meio-ambiente-noticias/7484-mprn-ingressa-com-acao-contra-prefeitura-de-natal-e-caern-pordesastreem-mae-luiza

Sá, C. P. (1998). A construção do objeto de pesquisa em representações sociais. EdUERJ.

Santos, R. F. dos. (2007). Vulnerabilidade ambiental: desastres naturais ou fenômenos induzidos? Ministério do Meio Ambiente.

Silva, J. C. S dos. (2016). Solidariedade e fortalecimento da resiliência comunitária em situação de desastre: O caso do Bairro de Mãe Luíza, Natal - RN. [Dissertação de mestrado, Universidade Federal do Rio Grande do Norte]. https://1library.org/title/solidariedade-fortalecimento-resiliencia-comunitariasituacao-desastre-bairro-luiza

Silva, V. P. da \& Andrade, L. M. C. A. (2019). Resíduos sólidos versus desastres urbanos: alguns aportes teóricos. In: André Cardim de Aguiar, Kardelan Arteiro da Silva, Soraya Giovanetti El-Deir. (Org.). Resíduos sólidos: impactos ambientais e inovações tecnológicas. EDUFRPE, 1, 17-29.

Souza, L. B., \& Zanella, M. E. (2009). Percepção de riscos ambientais: teoria e aplicações. Edições UFC. 240 p.

Tominaga, L. K., Santoro, J., \& Amaral, R. (2009). Desastres naturais: conhecer para prevenir. Instituto Geológicos.

Veyret, Y. (2007). Os riscos: o homem como agressor e vítima do meio ambiente. Ed. Contexto. 